\title{
Influencia del consumo en el crecimiento económico de los Conos Limeños
}

\author{
Marco A. PALACIOS RAMÍREZ
}

Según analistas del ${ }^{1}$ Banco Interamericano de Desarrollo (BID) la clase media tradicional para el año 2013 es aproximadamente $50 \%$ y la clase emergente es aproximadamente $20 \%$. Ambos porcentajes suman un total de $70 \%$ de la población del Perú. La clase baja es aproximadamente $28 \%$ y la clase alta es $2 \%$.

Los mismos analistas, señalan que el rango de ingresos para la clase media tradicional (su historia fue construida por los abuelos y los padres.) está entre S/.1,500 N. Soles y S/.3,600 N. Soles.

La clase emergente (su historia fue construida por ellos mismos) tiene un rango de ingresos de entre S/.900 a 1,500 N. Soles y S/.3,600 N. Soles, sin embargo es una población vulnerable a los cambios de la economía, los desastres naturales y otros factores externos.

Por otro lado, los analistas del grupo Santander son más optimistas y consideran que en el año 2013 la clase media en el Perú, se situaría alrededor del 57\% (Chile tiene aproximadamente un $77 \%$ de clase media) de la población, cifra que representa aproximadamente 16 millones 800 mil habitantes más o menos para el año 2013, repartidos en el territorio.

En el análisis que realizó el Grupo Santander, cuantificó el concepto de clase media usando el nivel de ingreso anual y el poder de compra de cada país, "US\$10 al día y \$ 300 mensual, por habitante para ser considerado dentro de este segmento".

Al existir una mayor proporción de individuos en la clase media; los cambios en la manera de hacer negocios es muy significativa en muchas empresas que ofrecen bienes y servicios, la tendencia al consumo se incrementa a la vez que crece la economía, sin embargo surgen problemas sociales.

1 Banco Interamericano de Desarrollo (BID) sede de Lima-Perú.

Estudio económico. "Clase Media en el Perú: Cuantificación y Evolución Reciente". 
Han surgido nuevos negocios en los conos de la ciudad de Lima en los últimos años.

Por ejemplo: Muchos negocios de los siguientes han tenido que reestructurar sus estrategias de negocios para el público de los conos:

Los negocios tradicionales de venta de automóviles, los negocios de modas, las empresas tradicionales de artefactos y electrodomésticos, las empresas inmobiliarias, las tiendas por departamento, otras tiendas de consumo masivo, etc.

Con la expansión económica de los años 90, se instalaron inicialmente tiendas por departamentos en los distritos tradicionales de Lima (Miraflores, San Isidro), sin embargo en muy poco tiempo, estas tiendas aperturaron sucursales en los conos de Lima (Independencia, Los Olivos).

\begin{tabular}{|l|r|c|}
\hline \multicolumn{3}{|l|}{ Población de Lima Región 8,445,211 habitantes. } \\
\hline Poblacón de Lima Metropolitana en el 2013. \\
\hline Lima Tradicional & 760,574 & $10 \%$ del total. \\
\hline Callao & $2,129,608$ & $28 \%$ del total. \\
\hline Conos & $4,715,560$ & $62 \%$ del total. \\
\hline Población Total. & $7,605,742$ & $100 \%$ \\
\hline Fuente: Municipalidad Metroplitana de Lima. \\
\hline
\end{tabular}

Los Conos concentran aproximadamente dos tercios de la población capitalina (Dos millones ochocientos mil personas, según datos de la ${ }^{2}$ Municipalidad de Lima Metropolitana al 2013).

Ello nos da un claro indicio del enorme potencial de negocios de los inversionistas extranjeros que tuvieron el olfato empresarial, para aprovechar a un segmento insatisfecho en sus necesidades de consumo.

Esta situación de negocios es también una buena oportunidad para las empresas nacionales de poco capital establecidas en la zona y las que proyectan establecerse en los conos que pueden aplicar el marketing, con todos sus conceptos y herramientas como el Benchmarking, el Merchandising, el Marketing BTL, la Mezcla de Marketing, etc.

Algunos indicadores psicográficos referidos a los estilos de vida de los conos son los siguientes: 1) Actividades socioeconómicas y culturales (Compras de vestidos y artefactos de línea blanca y marrón en las grandes tiendas de consumo

2 Estudio sobre la evolución demográfica de la población de Lima. Instituto Metropolitano de Planificación de la Municipalidad de Lima. 2012. 
masivo como Metro, Saga, Tottus, asistencia los fines de semana a conciertos de Cumbia Norteña y Conciertos de música Chicha). 2) Preferencia por el "Pollo a la Brasa acompañado con cervecitas", antes que una "parrilla con vino". 3) Opiniones sobre la educación que reciben los hijos en los colegios, institutos de enseñanza de idiomas y las universidades que ofertan carreras posicionadas en los conos.

Llama la atención ver las empresas de ventas de automóviles, de comida como chifas, pollerías, otros negocios como hoteles y tiendas por departamentos que se expanden desde Lima Tradicional hacia los Conos de Lima, como es el caso concreto desde el Distrito de San Isidro -Av.Javier Prado altura del Ex Cine Orrantia pasando hacia el Cono Este hasta llegar a la Carretera Central, en la cual hay numerosas empresas que venden autos japoneses, americanos, europeos y chinos. ¿Pero a qué se debe esa expansión? Muchas personas que habitan en la confluencia de La Molina Santa Anita y Ate realizan compras en las numerosas tiendas ubicadas alrededor de esta zona; estas empresas exhiben sus productos en grandes vitrinas que llegan a tener tres pisos de altura como sucede en Vitarte, lo cual motiva a las familias trabajadoras y consumidoras que adquieran sus vehículos de transporte, alimentación y vestido. Esta situación es conocida como el efecto psicológico del consumidor o Efecto demostración. Siguiendo la ruta hacia el Este en dirección de la Carretera Central, se ha inaugurado últimamente un nuevo Mall Plaza aparte de los centros comerciales que ya existían, es el caso de Santa Anita, donde un centro comercial conocido en la zona, es el número uno en venta de equipos informáticos a nivel nacional, pero no solo estos productos tienen precios bajos, sino ciertos alimentos, que son distribuidos no solo a los conos de Lima sino a otras regiones desde el Mercado de Productores de Santa Anita a la Sierra (Cerro de Pasco, Huancayo, Jauja y Tarma) en situaciones oligopólicas.

Esta estrategia geográfica y comercial de expandirse hacia los conos con más capacidad adquisitiva, atrae tanto a Lima tradicional como al resto de los pobladores del cono este que vienen a comprar sus bienes y servicios, como es el caso de los distritos de Ricardo Palma, Santa Eulalia, Chosica, Chaclacayo, Santa Clara, Ate, Santa Anita, La Molina, inclusive desde las provincias cercanas a Lima, como, Huancayo y Cerro de Pasco. Pero en la carretera Central no solo hay negocios que compiten en venta de productos de consumo masivo y ${ }^{3}$ servicios informáticos, sino también, los que ofrecen servicios médicos al instante y sin colas, servicios educativos al alcance del bosillo de los padres de familia, venta informal de vehículos usados entre camiones, autos y vehículos menores, como los triciclos de carga y motos lineales. En Ceres

3 Estudio de Mercado sobre la preferencia de bienes de consumo y servicios informáticos en el Cono Este de Lima. Realizado para la empresa Sayosistem SAC. Año 2013. 
Vitarte hay ejemplos de Marketing masivo en las tiendas de motocicletas de tres pisos como las vitrinas de los grandes almacenes, en las cuales puedes armar el modelo de tu moto con partes de la China o India, todos estos ejemplos anteriores resumen el marketing callejero, el marketing BTL, la innovación y la creatividad peruana.

Resumen:

El crecimiento de la economía en los últimos veinte años ha favorecido el surgimiento de la clase media tradicional y la clase emergente que en la actualidad ambas clases se sitúan aproximadamente en $70 \%$ de la población peruana.

Los Conos concentran aproximadamente dos tercios de la población capitalina, con una tendencia al consumo de $60 \%$, población que dinamiza el consumo de la capital. 